
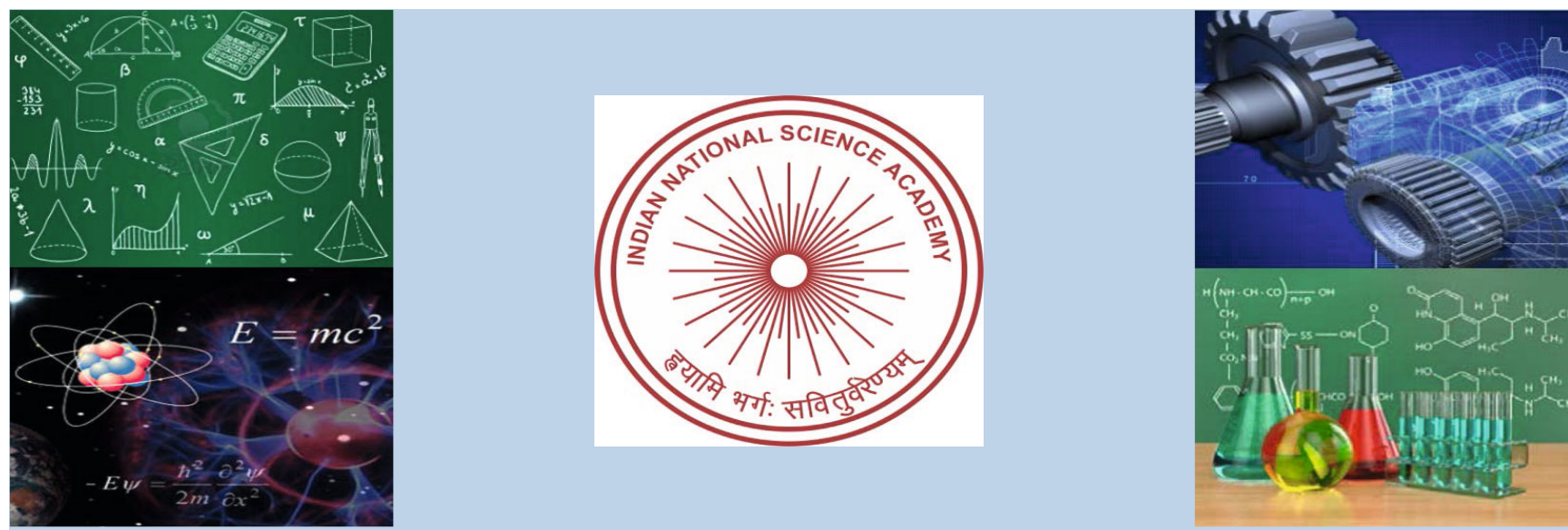

\title{
INDIAN NATIONAL SCIENCE ACADEMY BAHADURSHAH ZAFAR MARG, NEW DELHI 110002
}

\section{INSA TEACHERS AWARD-2015 CALL FOR NOMINATIONS}

To recognize and value excellence, consistency and high level of teaching in Indian Colleges, Universities and Institutions, the Academy has instituted the INSA Teachers Award. The award is made annually to recognize and honour teachers for providing guidance, inspiration and mentoring students to take up careers in Science and Technology. All disciplines of Science and Technology including Medical \& Engineering Sciences come under the purview of this award. The number of awards to be made in any year shall be up to 12. Each awardee will be presented a scroll, a cash award of Rs. 50,000/- and a onetime book grant up to Rs. $20,000 /$ -

The nominee should be currently working or worked till retirement in India, with at least 20 years of teaching experience at undergraduate or postgraduate level. A teacher may be nominated by Fellows of INSA, Principal of a College, ViceChancellor of a University, Director of an Institution, a colleague or by a former student who is associated with an academic / R\&D institution. The nominator may forward only one nomination in a year.

The last date for receipt of nominations is May 31, 2015. For details please visit our website www.insaindia.org.
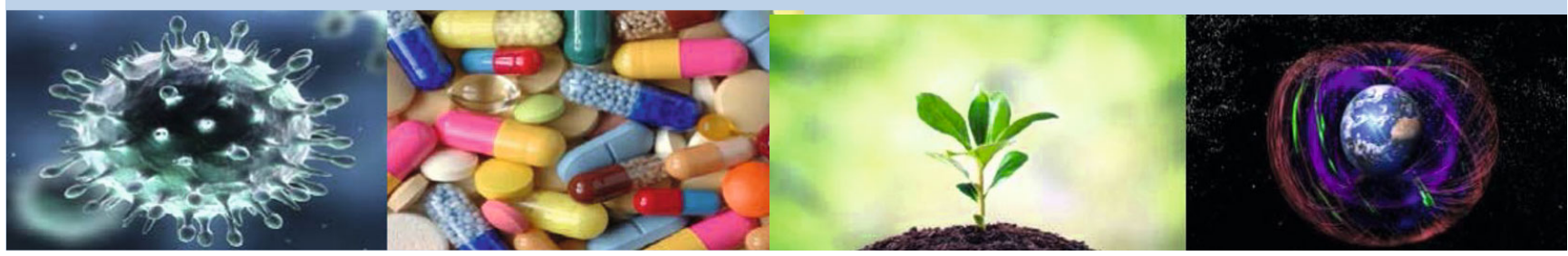